\title{
The caregiving experience: How much do health professionals understand?
}

\author{
Dianne Wynaden, Curtin University of Technology \\ Ursula Ladzinski, Curtin University of Technology \\ Jenny Lapsley, Curtin University of Technology \\ lan Landsborough, Curtin University of Technology \\ Janice Butt, Curtin University of Technology \\ Vivien Hewitt, Curtin University of Technology
}

Legal, social and economic factors have changed the delivery of care to people who have a mental disorder. Many of these people are now treated in the community and they live with or in close proximity to their family. The aim of this paper is to provide health professionals with an insight into the experience of being a caregiver to a person with a mental disorder. For these families caregiving becomes an integral part of everyday life.

Positive outcomes for both the caregiver and the ill family member are more likely to occur when effective levels of collaboration exist between health professionals and caregivers. Collaboration is enhanced when caregivers and health professionals value each other's contribution to the ill family member's care. Often the burden, stress, and socio-economic effects on the family caring for a person with mental illness is not sufficiently appreciated and further increases this burden. A review of the literature from the caregiver's perception is presented. An increased understanding of the caregiving experience will enable health professionals to develop and implement strategies that facilitate positive outcomes for the caregiver and the ill family member.

Key Words: families, collaboration, caregiver, mental illness, mental health professional, caregiver burden, mental disorder

Dianne Wynaden RN, RMHN, PhD, MANZCMHN, School of Nursing and Midwifery, Curtin University of Technology, Western Australia

Ursula Ladzinski BA, PGrad Dip Soc Research and Evaluation, School of Nursing and Midwifery, Curtin University of Technology, Western Australia

Jenny Lapsley RN, BAppSc, GDip (Nsg), MSc (Nsg), School of Nursing and Midwifery, Curtin University of Technology, Western Australia

lan Landsborough RMHN, RGN, ORMC, DN (London) BSc. (Nursing), M.Ed, School of Nursing and Midwifery, Curtin University of Technology, Western Australia Janice Butt RN, RM, ADM, PGCEA, MA(Ed), School of Nursing and Midwifery, Curtin University of Technology, Western Australia

Vivien Hewitt BSc (Hons) Grad Dip Lib, School of Nursing and Midwifery, Curtin University of Technology, Western Australia

Correspondence to:

Dr Dianne Wynaden, School of Nursing \& Midwifery, Curtin University of Technology, Western Australia

Email: d.wynaden@curtin.edu.au

\section{Introduction}

In Australia, one person in five will at some stage in their life experience the burden of a major mental disorder (Australian Bureau of Statistics 1998). Historically, people who have mental disorders were isolated from society in large stand-alone mental institutions on the outskirts of cities. The health care philosophy that sustained these large institutions also perpetuated the image that these people were dangerous and, therefore, unable to live in society (Kelly \& Stephens 1999).

Globally, social, legal and economic factors have dramatically changed the delivery of mental health care (Mechanic \& Rochefort 1990). Deinstitutionalisation, or the process of moving large numbers of psychiatric patients from isolated stand-alone psychiatric hospitals to the community, began in the United States of America during the 1950s (Jones 1996, Wilding 2000). In Australia, the process of deinstitutionalisation followed a similar path and consisted of three stages: 1) the reduction in stand-alone in-patient psychiatric beds; 2) the expanded provision of community based care; and 3) the integration or mainstreaming of mental health care services with other components of health care (Australian Health Ministers 1998, Australian Health Ministers 2003).

The provision of mental health care in the least restrictive environment and the integration of psychiatric care into the mainstream health care system is now the focus of Australian national mental health policy (Australian Health Ministers' Conference 1992, Australian Health Ministers 1998).

\section{The family as caregivers}

Currently, it is estimated that one in four families have a member with a mental disorder (Heffern 1993). These families play an increasingly important role in facilitating the provision of mental health services in the community (Boland \& Sims 1996). According to Skelton (1994) 'the present policy of treating mentally ill people in the community could not exist without carers who bear the main burden of care. ... carers are the glue that holds the system together' (p2).

Families were not always viewed as important and during the last century health professionals rejected and blamed them for contributing to the family member's illness. This left many families with extreme feelings of guilt (Doornbos 1996). Several types of 
mental disorders have now been reconceptualised as neurophysiological diseases with an associated chronic disability (Tuck et al 1997). Family is increasingly viewed as central to the rehabilitation and wellbeing of the ill family member. Moreover, community mental health care has shifted many of the responsibilities for the management of the family member's health care needs and costs from the health care system to 'the home care system' (Smitka 1998). The 'home care system' has made families responsible for the physical, emotional, financial and social tasks associated with caring for a family member at home (Reinhard 1994). According to Camann (1996) 'community care became by default family care with little understanding of the implications for families' (p481).

While caring for a person with a mental disorder in the home environment sets the stage for purposeful and meaningful involvement in life (Roberts \& Fitzgerald 1991), the family is also confronted with managing behaviours that are rarely encountered by most families (Reinhard 1994). When thrust into the caregiving role, many families display a range of responses and emotions such as fear, anger, self-blame, or guilt (Peternelj-Taylor \& Hartley 1993).

In $1963 \mathrm{Grad}$ and Sainsbury first described the strain on families posed by the caregiving role (Saunders 1997) and it is widely acknowledged that mental disorders create burden for caregivers (Rose 1996). Family functioning, relationships and roles, financial security and stability, level of mental health, coping and adjustment are altered, sometimes permanently, as a result of this burden (Bernheim \& Lehman 1985, Marsh 1992, Jeon \& Madjar 1998). In 1966 Hoenig and Hamilton described the objective and subjective components of the burden experienced by caregivers. Despite decades of research this burden is not well understood and remains a problem for families (Maurin \& Boyd 1990, Rose 1997).

\section{Why do families take on the caregiving role?}

When assessing the level of burden a family experiences, it is important to identify the reasons why they make the commitment to care. A study by Jablensky and colleagues (1999) found that 42 percent of family caregivers of people with mental disorders were women and they were often the ill person's mother. Historically, there has been a gender and ideologically based assumption that it is natural for women to want to care (Lee 2001). As yet we do not fully understand the impact of the societal expectation that women will care for sick family members. While it is acknowledged that it is middle-aged women who are most likely to provide care (Orbell 1996), these women are themselves a very vulnerable group and often have reduced social and economic power. According to Lee (2001) these women place the needs of others before their own needs and '... may also be more likely than younger women to have internalized [sic] the concepts underlying traditional gender roles, accepting that women have a "natural" responsibility to care for family members ... (p394)

Many public policies and ideologies support the notion of a shared sense of obligation that family members will care for each other. These ideologies are touted as reflecting the rightful role of the family in the scheme of nature (Karp \& Watts-Roy 1999).
However, as early as 1989, Fitch concluded that not all families were willing to take on the caregiving role and that in reality '[the family] does not operate to the kind of fixed rules that caring is 'naturally' a part of the family relationship' (p240). Caregiving impacts on all areas of family life and the impact is reflected through each family member's behaviours, feelings, and emotions (Kellett \& Mannion 1999).

King et al (1995) provided further insight into the reasons why families make the commitment to care. Their research identified that families' commit to the caring because they: 1) feel obligated; 2) are owners of their own difficulties; 3) believe that a family should protect vulnerable members; and 4) feel that families are self-reliant units. Kellett and Mannion (1999) identified similar themes, which were based on the concepts of reciprocity in the relationship: families are obligated to care; the belief that home care is the best care for the affected family member; and the positive outcomes of providing care within the family. Brown and Stetz (1999) also reported that a family's willingness to care was based on the sense of obligation and reciprocity the relationship with the ill person what the ill person would allow to occur and what the caregiver was willing to contribute. One or more of these themes may determine a family's ongoing commitment to caregiving even when the personal cost to family life is considerable.

More recently other researchers (Kavanagh 1995, Falloon et al 1996) have suggested that, while experiencing considerable burden, families commit to care because they receive positive outcomes from the experience. These families view the ill member as making a valuable contribution to family life. The contributions include such things as providing comfort, helping with household chores, and providing the carer with a meaning and purpose to life.

\section{Understanding the caregiving experience}

The caring experience has many dimensions (Bernheim \& Lehman 1985, Browning \& Schwirian 1994, Nankervis et al 1997) and poses demands which may last for years. The failure of health professionals to understand the family caregiving experience and the reinforcement of societal expectations that all families will take on the caring role (Jeon \& Madjar 1998) may result in family members experiencing increased levels of burden. Many factors impact on the level of caregiving burden experience by families and these include the developmental stage of the family (Cook et al 1994, Rose 1997), whether the ill member lives at home (Jones et al 1995) and socioeconomic status (Biegel et al 1994). Although the caregiver burden may not be obvious to people outside the family, it impacts on the family's level of resilience and their continued commitment to care.

Camann (1996) reported that families often provided care with limited support and resources from the health care system. They received little information from health professionals and may not be included in the decision-making process. Families were left to construct their own meaning of the mental disorder, its causes and consequences and they received little financial support, incentive, acknowledgment, or assistance for the role they undertook (Jeon \& Madjar 1998). Every member of the 
family is affected by the caregiving experience and, while community programs focus on the well being of the consumer, they do not generally support and meet the needs of the family. Caregivers must reconcile obligation and love for the family member with the emotions of fear, bewilderment, loneliness, exhaustion, depression, frustration, guilt, resentment, anger, and even hate (Karp \& Tanarugsachock 2000, Chambers et al 2001). These emotions change regularly throughout different phases of the caregiving process. A significant problem appears to be the continual volume and volatility of emotions experienced by caregivers and ill family members. Caregivers reported that they were repeatedly trying to complete their obligations to the ill person while simultaneously managing an array of changing feelings and emotions (Karp \& Tanarugsachock 2000, Wynaden 2003).

It is argued that the current body of knowledge on family caregiving has constrained the ability to understand the depth of the experience (Kellett 1996, 1997). Irrespective of our current level of understanding, family caregiving is increasingly a reality in an economic climate of reduced public spending on health and welfare services. According to Lee (2001) family care has been disguised by the 'rhetoric of community care' (p394) and although some researchers have demonstrated that families obtain satisfaction and a sense of self-worth from caregiving (O'Connor et al 1990, Cohen et al 1994) families continue to experience considerable burden (McKinlay et al 1995).

\section{Strategies for caregiver support}

Globally, mental health reforms have led to substantial changes in health care delivery (Lloyd \& King 2003). While the increasing trend to provide mental health care within the community setting has obvious political and economic gains, the psychosocial and emotional impact of this strategy on family caregivers is much more difficult to measure. According to Backlar (1997), despite the large amount of research on family burden, there remains a lack of understanding about the relationship between caregivers, the cared for, and formal services. While the caregiving experience may have positive outcomes for some families it also brings burden, worry and an array of emotional responses (van Manen 2002). Whatever the reason behind the commitment to care, most families provide care with limited help, support, or recognition of their contribution.

Globally, mental health strategies advocate the involvement of caregivers in decision making, advocacy and outcome measures. These strategies encourage the engagement of carers at macro and micro level in clinical service planning and treatment decisions (Lloyd \& King 2003). At a clinical level health professionals must work towards the inclusion of carers in a collaborative relationship, eliminating the gap between espoused policies and perceived reality. According to Backlar (1997) there may be vast differences between the therapeutic goals of clinicians and the outcomes evidenced in the daily lives of caregivers. While the success and expansion of community mental health care is dependent on the goodwill and health of families to care for ill family members (Walker \& Dewar 2000), collaboration between health professionals and caregivers currently appears limited (Wynaden 2003).
Caregivers value the service provided to the ill family member but appear less satisfied with the extent to which their own needs are recognized (Solomon et al 1998). They require involvement with health professionals as well as information about the ill family member's illness, management and the support systems available to them. Service providers may hold expectations that families will care for the ill family member yet fail to provide families with information to assist with this process (Pejlert 2001). Caregivers may be unable to express their needs and, therefore, health professionals need to consciously assess and address their day-to-day concerns (Chafetz \& Barnes 1989). In 1993 the Human Rights and Equal Opportunity Commission highlighted the need for families to have accessible support and access to acute care services to maintain the ill family member at home. This increased level of support is deemed necessary to ensure that the family remains committed to provide care within the community (Burdekin et al 1993).

The documented experiences of caregivers across a variety of enduring illnesses demonstrate similarity in the descriptions of expressed burden (Walker \& Dewar 2000). In a national survey of 1500 carers, 59\% reported their physical health was worse because of their caring responsibilities, while $85 \%$ identified detrimental changes to their level of emotional health (Carers NSW 2003). Of the 1500, those caring for a family member with a mental disorder reported that the negative attitudes of health professionals and the general public contributed to the deterioration in their own health status.

Strategies to assess impact and minimise the level of carer burden were not identified and/or implemented in the Western world prior to the process of deinstitutionalisation. These strategies may have included: the provision of adequate and effective support and services to caregivers; access to emergency services; education for health professionals regarding the needs of carers; and education of the general population about mental disorders, treatment and rights. These strategies may have decreased caregiver burden by reducing stigma and increasing the level of community support and understanding toward people with mental disorders and their families.

Health professionals whose philosophy of care encompasses assessment of the ill family member, the primary carer, family and social networks are more adept in developing a comprehensive picture of the stresses that regularly confront caregivers (Wynaden \& Orb 2005). By acknowledging the human experience attached to caregiving, health professionals increase their awareness and understanding of the value and role caregivers play in the ill family member's life.

Providing caregivers with appropriate support is a challenge for both health professionals and policy makers. This requires a new approach to policy and planning, educational preparation of health professionals, and strategies to foster collaborative partnerships with caregivers at all levels as required by the National Mental Health Plan 2003-2008 (Australian Health Ministers 2003). Education of the general population needs to take into consideration the important role and needs of caregivers caring for a person with a mental disorder if the reality of effective 
community mental health care, as opposed to political rhetoric, is to be achieved. The Enhancing Relationships with Health Professionals, Consumers and Carers Project (Mental Health Council of Australia 2000) has identified a number of barriers to effective community care. Section 9 of this report outlines strategies to overcome these barriers, through five key areas of: consumer and carer participation; continuous quality improvement; collaborative implementation of mental health legislation; workplace reform; and education and training.

Allen (2000) argues 'empowering the clients and their caregivers can only be accomplished, if nurses are themselves empowered' (p151). Health professionals are often constrained in their ability to involve caregivers as a result of the acuity of illness and staffing levels in many health settings (Wynaden et al 2001), leaving both caregivers and health professionals with feelings of disempowerment. Casey (1995) reported that the level of caregiver involvement was dependent upon health professionals' perception of how and when caregivers should be involved. Many health professionals excluded carers because of prior negative interactions with them (Allen 2000). Caregivers have an unequal distribution of power when negotiating an active role in the ill family member's care because the health care environment is alien to them and weighted in favour of the health professional (Walker \& Dewar 2001). As a result caregivers may direct their anger and frustration towards health professionals which may lead to stereotyping of caregivers as emotionally volatile. These encounters may result in defensive interactions between health professionals and caregivers (Walker \& Dewar 2001). Most government policies aim to facilitate the development of health services that are more accountable to consumers and caregivers (Mental Health Council of Australia 2000). In reality it is clinicians who bring about change and they must be cognisant of policy frameworks and be adequately supported and resourced.

The majority of caregivers are unfamiliar with the health care system. They are unsure of what contribution or role they can play in the affected family member's care or what opportunities are available to them. What constitutes a satisfactory level of involvement may differ between caregivers, and professionals may be unclear about the caregiver's level of involvement. Health professionals can improve collaboration with caregivers in a number of areas (Chambers et al 2001, Lloyd \& King 2003). These include: providing support; providing education on mental disorders, their management and dealing with family issues and conflict; working with families to decrease family distress or dysfunction; improving caregivers' coping skills; improved communication with caregivers; information on how to access community services; dealing with caregivers' emotions; involving the caregiver in longterm planning; and helping caregivers to adapt and change their care giving role over time. These areas provide a framework for ongoing collaborative involvement, which in turn can further increase the caregiver's level of self-efficacy and self-confidence.

Community mental health care offers a more creative, flexible approach to the treatment of mental disorders in society (Australian Health Ministers 1998). While collaboration between health professionals and caregivers is advocated in policy documents, many health professionals do not fully understand what families experience when they make the commitment to care for an ill family member. With the third stage of the Australian National Mental Health Plan (2003-2008) currently being implemented under the National Mental Health Strategy (Department of Health and Aged Care 1997) there needs to be greater emphasis on collaborative consumer, professional, and carer strategies to improve communication, decision-making and the provision of support for families.

\section{Conclusion}

The introduction of mental health care into the community has made considerable progress over the last decade. However, recent reports highlight significant personal costs associated with care giving in the community. Families committed to caring for a family member with mental illness experience high levels of stress and socio-economic disadvantage. Health professionals and policy makers need to develop greater insight into the care giving experience, interact with caregivers more collaboratively, and implement strategies that facilitate better outcomes for all members of the family.

\section{References}

Allen D 2000 Negotiating the role of expert carers on an adult hospital ward. Sociology of Health and IIIness 22(2):149-171

Australian Bureau of Statistics 1998 Mental health and wellbeing: profile of adults, Australia, 1997. Australian Bureau of Statistics, Canberra

Australian Health Ministers 1998 Second national mental health plan: National Mental Health Strategy. Commonwealth Department of Health and Family Services, Canberra Australian Health Ministers 2003 National Mental Health Plan 2003-2008: National Mental Health Strategy. Commonwealth of Australia, Canberra

Australian Health Ministers' Conference 1992 National mental health policy. National Mental Health Strategy. Australian Government Publishing Service, Canberra

Backlar P 1997 Ethics in community mental health care: can we bridge the gap between the actual lives of persons with serious mental disorders and the therapeutic goals of their providers. Community Mental Health Journal 33(6):465-471

Bernheim K, Lehman A 1985 Working with families of the mentally ill. W.W. Norton Publishing, New York

Biegel D, Milligan S, Putnam P, Song L 1994 Predictors of burden among lower socioeconomic status caregivers of persons with chronic mental illness. Community Mental Health Journal 30(5):473-494

Boland D L, Sims S L 1996 Family care giving at home as a solitary journey. Image: The Journal of Nursing Scholarship 28(1):55-58

Brown M, Stetz K 1999 The labor of caregiving: a theoretical model of caregiving during potentially fatal illness. Qualitative Health Research 9(2):182-197

Browning J, Schwirian P 1994 Spousal caregivers' burden: impact of care recipient health problems and mental status. Journal of Gerontological Nursing 20(3):17-22 Burdekin B, Guilfoyle M, Hall D, Human Rights and Equal Opportunity Commission 1993 Human rights and mental illness: report of the national inquiry into the human rights of people with mental illness. Australian Government Publishing Service, Canberra Camann M 1996 Family-focused mental health care policy. Issues in Mental Health Nursing 17(5):479-486

Carers NSW 2003 Response to the consultation paper on the National Mental Health Plan 2003-2008. Retrieved January 82001 from the World Wide Web: http://www.carernsw.asn.au

Casey A 1995 Partnership nursing: influences on involvement of informal carers. Journal of Advanced Nursing 22(6):1058-1062

Chafetz L, Barnes L 1989 Issues in psychiatric caregiving. Archives of Psychiatric Nursing 3(2):61-68

Chambers M, Ryan A, Connor S 2001 Exploring the emotional support needs and coping strategies of carers. Journal of Psychiatric and Mental Health Nursing 8(2):99-106

Cohen C, Gold D, Shulman K, Zucchero C 1994 Positive aspects in caregiving: an overlooked variable in research. Canadian Journal on Aging 13(3):378-391 
Cook J, Lefley H, Pickett S, Cohler B 1994 Age and family burden among parents of offspring with severe mental illness. Journal of Orthopsychiatry 64(3):435-447 Department of Health and Aged Care 1997 National mental health report 1997: fifth annual report, changes in Australia's mental health services under the National Mental Health Strategy 1996-97. Department of Health and Aged Care, Canberra Doornbos M 1996 The strengths of families coping with serious mental illness. Archives of Psychiatric Nursing 10(4):214-220

Falloon I, Magliano L, Graham-Hole V, Woodroffe R 1996 The stress of caring for disabling mental disorders in a home based rehabilitation service. Journal of Nervous and Mental Disease 184(6):381-384

Fitch J 1989 Family obligations and social change. Polity Press, Cambridge Heffern R 1993 Our society is still giving mental illness a bum rap. National Catholic Reporter 29(33):18-20

Hoenig J, Hamilton M 1966 The schizophrenic patient in the community and his effect on the household. International Journal of Social Psychiatry 12(3):165-176 Jablensky A, McGrath J, Herrmen H, Castle D, Gureje 0, Morgan V, Horten A 1999 People living with psychotic illness: an Australian study. Retrieved 1 March 2000 from the World Wide Web: http://www.health.gov.au/hsdd/mentalhe.htm Jeon Y, Madjar I 1998 Caring for a family member with chronic mental illness. Qualitative Health Research 8(5):694-706

Jones S 1996 The association between objective and subjective caregiver burden. Archives of Psychiatric Nursing 10(2):77-84

Jones S, Roth D, Jones P 1995 Effect of demographic and behavioural variables on burden of caregivers of chronic mental ill persons. Psychiatric Services 46(2):141-145 Karp D, Tanarugsachock V 2000 Mental illness, caregiving, and emotional management. Qualitative Health Research 10(1):6-25

Karp D, Watts-Roy D 1999 Bearing responsibility: how caregivers to the mentally ill assess their obligations. Health 3(4):469-491

Kavanagh D 1995 Family interventions in mental disorder. Current Opinion in Psychiatry 8(3):130-133

Kellett U 1996 Caring in nursing homes: the family perspective. Geriaction 14(4):18-23 Kellett U 1997 Heideggerian phenomenology: an approach to understanding family caring for an older relative. Nursing Inquiry 4(1):57-65

Kellett U, Mannion J 1999 Meaning in caring: reconceptualizing the nurse-carers' relationship in community practice. Journal of Advanced Nursing 29(3):697-703 Kelly J, Stephens I 1999 Community case management for mental illness. Australian Nurses Journal 6(10):24-26

King S, Collins C, Liken M 1995 Values and the use of community services. Qualitative Health Research 5(3):332-347

Lee C 2001 Experience of family caregiving among older Australian women. Journal of Health Psychology 6(4): 393-404

Lloyd C, King R 2003 Consumer and carer participation in mental health services. Australasian Psychiatry 11(2):180-184

Marsh D 1992 Families and mental illness: new directions in professional practice. Praeger Publishers, New York

Maurin J T, Boyd C B 1990 Burden of mental illness on the family: a critical review. Archives of Psychiatric Nursing 4(2):99-107

McKinlay J, Crawford S, Tennstedt S 1995 The everyday impacts of providing informal care to dependent elders and their consequences for the care recipients. Journal of Aging and Health 7(4):497-528

Mechanic D, Rochefort D 1990 Deinstitutionalisation: an appraisal of reform. Annual Review of Sociology 16:301-327
Mental Health Council of Australia 2000 Enhancing relationships between health professionals and consumers and carers: final report. Commonwealth Department of Health and Aged Care, Canberra

Nankervis J, Bloch S, Murphy B, Herrman H 1997 A classification of family caregivers' problems as described by counsellors. Journal of Family Studies 3(2):169-182

O'Connor D, Pollitt P, Roth M, Brook C, Reiss B 1990 Problems reported by relatives in a community study of dementia. British Journal of Psychiatry 156:835-841

Orbell S 1996 Informal care in social context: a social psychological analysis of participation, impact and intervention in care of the elderly. Psychology and Health 11(1):155-178

Pejlert A 2001 Being a parent of an adult son or daughter with severe mental illness receiving professional care: parents' narratives. Health and Social Care in the Community 9(4):194-204

Peternelj-Taylor C, Hartley V 1993 Living with mental illness: professional/family collaboration. Journal of Psychosocial Nursing 31(3):23-28

Reinhard S 1994 Perspectives on the family's caregiving experience in mental illness. Image 26(1):70-74

Roberts K, Fitzgerald L 1991 Serenity: Caring with perspective. Scholarly Inquiry for Nursing Practice 5(2):127-146

Rose L 1996 Families of psychiatric patients: a critical review and future research directions. Archives of Psychiatric Nursing 10(2):67-76

Rose L 1997 Caring for caregivers: perceptions of social support. Journal of Psychosocial Nursing 35(2):17-24

Saunders J 1997 Walking a mile in their shoes....symbolic interactionism for families living with severe mental illness. Journal of Psychosocial Nursing 35(6):8-13, 45-46

Skelton J 1994 ARAFMI Newsletter: Association of Relatives and Friends of the Mentally III (NSW) 53:2

Smitka J 1998 Using nursing research to assess families managing complex home care. Kansas Nurse 73(4):1-2

Solomon P, Draine J, Mannion E, Meisel, M. 1998 Increased contact with community mental health resources as a potential benefit of family education. Psychiatric Services 49(3):333-339

Tuck I, DuMont P, Evans G, Shupe J 1997 The experience of caring for an adult child with schizophrenia. Archives of Psychiatric Nursing 11(3):118-125

van Manen M 2002 Care-as-worry, or "don't worry, be happy". Qualitative Health Research 12(2):262-278

Walker E, Dewar B J 2000 Moving on from interpretivism: an argument for constructivist evaluation. Journal of Advanced Nursing 32(3):713-720

Walker E, Dewar B J 2001 How do we facilitate carers' involvement in decision making? Journal of Advanced Nursing 34(3):329-337

Wilding C 2000 Improving quality of life after deinstitutionalisation through "ordinary adventure": a camping experience. Journal of Leisurability 27(1). Retrieved 9 Sept 2001 from the World Wide Web http://www.lin.ca/resource/htmI/Nol27/N27NIA3.htm

Wynaden D 2003 The primary carer's experience of caring for a person with a mental disorder in the Western Australian community: a grounded theory study. Unpublished Doctoral dissertation Curtin University of Technology, Perth, Western Australia Wynaden D, McGowan S, Chapman R, Castle D, Lau P, Headford C, Finn M 2001 Types of patients in a psychiatric intensive care unit. Australian and New Zealand Journal of Psychiatry 35(6):841-845

Wynaden D, Orb A 2005 Impact of patient confidentiality on carers of people who have a mental disorder. International Journal of Mental Health Nursing 14(3):166-171 